\title{
Integrating maintenance strategies in autonomous production control using a cost-based model
}

\author{
Robert Glawar ${ }^{1}$, Fazel Ansari ${ }^{1,2}$, Zsolt János Viharos ${ }^{3,4}$, Kurt Matyas ${ }^{2}$, Wilfried Sihn ${ }^{1,2}$ \\ ${ }^{1}$ Fraunhofer Austria Research GmbH, Theresianumgasse 7, A-1040, Vienna, Austria, \\ 2 TU Wien, Institute of Management Science, Theresianumgasse 27, A-1040, Vienna, Austria \\ ${ }^{3}$ Institute for Computer Science \& Control (SZTAKI), KendeStr.13-17, H-1111, Budapest, Hungary \\ ${ }^{4}$ John von Neumann University, Izsáki u. 10, H-6000, Kecskemét, Hungary
}

\section{ABSTRACT}

Autonomous production control (APC) is able to deal with challenges, inter alia, high delivery accuracy, shorter planning horizons, increasing product and process complexity, and frequent changes. However, several state-of-the-art approaches do not consider maintenance factors contributing to operational and tactical decisions in production planning and control. The incomprehensiveness of the decision models and related decision support tools cause inefficiency in production planning and thus lead to a low acceptance in the manufacturing enterprises. To overcome this challenge, this paper presents a conceptual cost-based model for integrating different maintenance strategies in autonomous production control. The model provides relevant decision aspects and a cost function for different maintenance strategies using on a market-based approach. The present work thus makes a positive contribution to cope with the high demands on flexibility and response times in planning while at the same time ensuring high plant productivity.

\section{Section: RESEARCH PAPER}

Keywords: Maintenance; autonomous production control; production planning; cyber physical systems; industry 4.0

Citation: Robert Glawar, Fazel Ansari, Zsolt János Viharos, Kurt Matyas, Wilfried Sihn, Integrating maintenance strategies in autonomous production control using a cost-based model, Acta IMEKO, vol. 10, no. 3, article 22, September 2021, identifier: IMEKO-ACTA-10 (2021)-03-22

Section Editor: Lorenzo Ciani, University of Florence, Italy

Received February 9, 2021; In final form May 2, 2021; Published September 2021

Copyright: This is an open-access article distributed under the terms of the Creative Commons Attribution 3.0 License, which permits unrestricted use, distribution, and reproduction in any medium, provided the original author and source are credited.

Funding: This work has been supported by the European Commission through the H2020 project EPIC (Grant No. 739592)

Corresponding author: Robert Glawar, e-mail: robert.glawar@fraunhofer.at

\section{INTRODUCTION}

In today's competitive market, manufacturing enterprises are faced with the challenge of achieving high productivity, short delivery times and a high level of delivery capability despite evershorter planning horizons, a large number of external planning changes and increasing planning complexity [1], [2]. This high degree of complexity in planning is no longer effectively and affordably manageable for humans [3]. On the one hand, there are high demands on flexibility and reaction times in planning and, on the other hand, high requirements regarding availability of production facilities, equipment and machines [4].

However, current systems for production planning and control (PPC) neither incorporate technical innovations nor social requirements and are therefore not able to meet the current challenges [5]. Likewise, current maintenance processes and strategies are not sufficiently prepared for these challenges [6].
Considering the advancement towards Industry 4.0, new opportunities arise due to innovative technologies and approaches such as Industrial Internet of Things (IIoT) applications [7], horizontal and vertical communication within a production system by means of Open Platform Communications Unified Architecture (OPC UA) [8] or the use of artificial intelligence (AI) methods for data analysis, forecasting, optimization and planning [9].

The degree of autonomy of such a cyber physical production system (CPPS) describes the ability to plan, control and initiate actions autonomously [10]. Approaches to autonomous production control (APC) represent suitable ways to increase the degree of autonomy of a CPPS [11], [12]

Therefore, APC represent suitable possibilities to deal with the aforementioned requirements [13].

However, these approaches are currently limited to lab research and are not ready for industrial applications [14]. Most of the current approaches are based on idealised assumptions such as maximum availability (i.e. $95-98 \%$ ) or do not take many 
Table 1. Overview Maintenance in autonomous production control.

\begin{tabular}{|c|c|c|c|c|c|c|c|c|c|}
\hline & & \multicolumn{8}{|c|}{ Focus on: } \\
\hline Authors & Title & 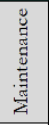 & 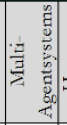 & $\frac{3}{4}$ & 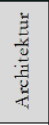 & 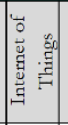 & 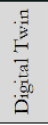 & 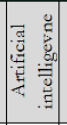 & 苟 \\
\hline Cupek et al. [19] & Agent-based manufacturing execution systems for short-series production scheduling & & + & & & & & & \\
\hline F.rol and Sihn [3.3] & Intelligent Production Planning and Control in the Cloud - Towards a Scalable Software Architecture & + & & & + & + & & & \\
\hline Fernandes et al. [16] & Improving materials flow through autonomous production control & & & & & & + & & \\
\hline Hoffmann et al. [26] & Intelligence Produktionssteuerung und Automatisierung & & + & & + & + & & & \\
\hline Graessler and Poehler [27] & Intelligent Devices in a Decentralized Production System Concept & & & + & & & + & & \\
\hline Grundstein et al. [22] & A new method for autonomous control of complex job shops & & & & & & + & & \\
\hline Gyulai et al. [31] & Online lead time prediction supporting situation-aware production control & & & & & & + & + & \\
\hline Jamrus et al. [30] & I Iybrid particle swarm optimization combined with genetic operators for flexible job-shop scheduling & & + & & & & & + & \\
\hline Kuhnle et al. [32] & Autonomous order dispatching in the semiconductor industry using reinforcement learning. & & & & & & & + & \\
\hline Kasakow et al. [18] & Event-driven production planning and control based on individual customer orders & & & & & & & & $\mathrm{x}$ \\
\hline Mantravadi et al. [24] & Multi-agent Manufacturing Execution System: Concept, architecture \& ML algorithm for a smart factory case. & & + & & + & & & + & \\
\hline Martins et al. [23] & Autonomous production control: A literature review & & & & & & & & + \\
\hline Mayer and Endisch [28] & Adaptive Production Control in a Modular Assembly System Based on Partial Look-Ahead Scheduling. P & & & & & & & + & \\
\hline Meissner et al. [21] & Analysis of Control Architectures in the Context of Industry 4.0 & & & & + & + & & & \\
\hline Pantförder et al. [25] & Agentenbasierte dynamische Rekonfiguration von vernetzten intelligenten Produktionsanlagen & & + & & + & + & & & \\
\hline Regulin and Voggl-Heuscr [14] & Agcntenoricnticrte Verknüpfung existicrender heterogencr automatisicrter Produktionsanlagen durch mobile Roboter & & $\mathrm{x}$ & & & & & & \\
\hline Vallhagen et al. [34] & Advanced usc of Data as an Enabler for Adaptive Production Control using Mathematical Optimization & $\mathrm{x}$ & & & । & & & & \\
\hline Wang ct al. [35] & Condition-based Real-time Production Control for Smart Manufacturing Systems & $\mathrm{x}$ & & & 1 & & 1 & & \\
\hline Zhang ct al. [17] & Multi-Agcnt-Bascd Production Planning and Control & & 1 & & & & & & \\
\hline Zou ct al. [29] & Resilicnt adaptive control based on renewal particle swarm optimization & & & & & & & 1 & \\
\hline
\end{tabular}

decisive factors such as maintenance strategies into account. For example, the question such as "how the current state of a production plant or machine can affect production control" is not taken into consideration [15]. Exactly these factors, as exemplified, are decisive for the acceptance and implementation maturity of autonomous approaches in industrial companies. Hence, the aim of the present work is to take a further step towards implementation maturity by integrating different maintenance strategies in APC.

\section{MAINTENANCE IN APC}

Autonomous production control (APC) has the potential to deliver optimal and resource efficient processes as well as higher quality and variations of products than conventional, centralized decision-making systems [16] Adaptive, decentralised production control can reduce planning efforts [17], enable shorter reaction times in planning [18] and create greater planning flexibility [19].

Since in most cases not all decisions in a production system are made autonomously, a CPPS typically includes a combination of hierarchical and heterarchical mechanisms for control [20]. Since approaches to autonomous production control are able to deal quickly and flexibly with unplanned changes within the production system, they are used in the context of CPPS to represent decision-making processes that require a high degree of responsiveness [21].

To ensure high level of acceptance among operational planning staff, it is particularly important that the underlying models comprehensively take relevant factors of the production system into account and thus making robust decisions [22]. Current studies show that a large number of research activities are concerned with the development of approaches to autonomous production control [23].

Current approaches focus on the description of the interactions between different parts of a production system from different perspectives. A typical task is to assign a waiting workpiece, which is to be processed in the course of a production job, to a machine or a workstation taking into account available resources, logistical parameters and the smoothing of the job load. Existing APC approaches are usually either carried out as event-driven sequencing [18] or agent-based sequencing [24].

First examples that the agent-based simulation is a suitable possibility to realize APC by using multi-agent systems are shown by Pantförder et al. (2017) [25]. The integration of such an approach in a production system on the basis of the UPC-UA standard is shown by Hoffmann et al. (2016) [26]. A key success factor for autonomous interaction in this context is the design of a of a robust system [27].

In order to reach such a design, different algorithms may be used to schedule the orders. In particular, genetic and evolutionary algorithms [28], swarm-based algorithms [29], [30], and market models [14] have been successfully used for APC. In addition, many current approaches to PPC rely on the application of methods of artificial intelligence. Often, ML is applied, for example, to predict lead times predict and optimize resource utilization [31]. In addition, reinforcement learning is used to enable, for example, an autonomous order scheduling system [32].

However, as shown in Table 1, few approaches deal with the integration of maintenance strategies in APC systems. For instance, Erol and Sihn (2017) presented a cloud-based architecture for intelligent production planning and control considering maintenance [33]. Vallhagen et al. (2017) also presented a system and information infrastructure to enable optimized adaptive production control [34]. Nevertheless, neither of these approaches explain which aspects of maintenance should be considered and how they should be integrated. In the approach presented by Wang et al. (2018), the condition of production plants is automatically evaluated and thus the production sequence is intelligently adapted. System 
Table 2. Aspects and their importance for APC integration into PPC system evaluated by various domain experts [36]

\begin{tabular}{|c|c|c|c|c|c|c|c|c|c|c|}
\hline Degree of Relevance & Symbol & \multirow{6}{*}{ 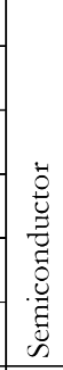 } & \multirow{6}{*}{ 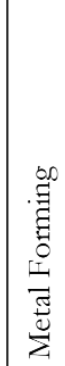 } & \multirow{6}{*}{ 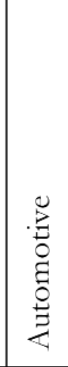 } & \multirow{6}{*}{ 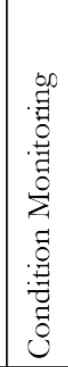 } & \multirow{6}{*}{ 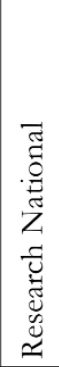 } & \multirow{6}{*}{ 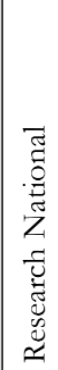 } & \multirow{6}{*}{ 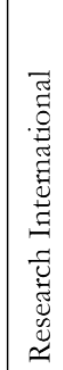 } & \multirow{6}{*}{\multicolumn{2}{|c|}{ 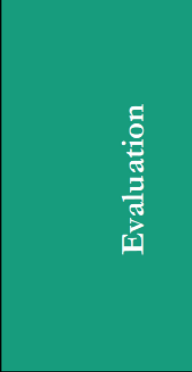 }} \\
\hline iery low relenance & 0 & & & & & & & & & \\
\hline Low relevance & $\Theta$ & & & & & & & & & \\
\hline medium relevance & (1) & & & & & & & & & \\
\hline bigh relexance & $\bullet$ & & & & & & & & & \\
\hline wry bigh reletance & & & & & & & & & & \\
\hline Maintenance relevant aspects & Relevant for the integration into: & \multicolumn{7}{|c|}{ Assessment of Experts } & & Overall \\
\hline downtime \& costs & production control & 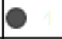 & ○ & ? & 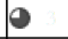 & ? & 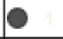 & 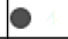 & O & Very I ligh \\
\hline repair time $\&$ costs & production control & (1) & 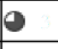 & P & 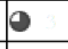 & (1) & O & O & $\Theta$ & High \\
\hline service time \& costs & production control & 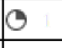 & ( & 8 & $\theta$ & . & 8 & ( & $\Theta$ & High \\
\hline availability of spare parts & production control & 1 & (1) 2 & (1) & P & 0 & 03 & . & $\theta$ & Iigh \\
\hline availability of maintenance personnel & production control & 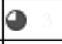 & 12 & (12 & (1) & 8 & ( & 0 & (e) & High \\
\hline availability Qualification & production control & $\theta$ & 1 & (1) & $\theta$ & 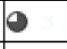 & $\theta$ & 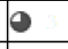 & $\Theta$ & High \\
\hline planned maintenance orders & production control / production planning & P & P & P & ? & P & 1 & $\odot$ & 0 & Very High \\
\hline probability of failure & production control / production planning & $\theta$ & 0 & ? & (1) & $\theta$ & . & O & 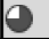 & I ligh \\
\hline condition of the system components & production control / production planning & P & $\Theta$ & P & 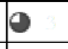 & O & (1) & (1) & (e) & High \\
\hline service intervals & production planning & - & 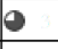 & P & e & . & (1) & 12 & $\Theta$ & High \\
\hline technical plant availability & production planning & 8 & P & $\theta$ & e & 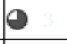 & (1) & 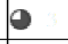 & 0 & High \\
\hline maintenance quota & production planning / production controlling & 0 & 0 & 0 & ( & ( & 0 & 12 & 9 & Low \\
\hline planned availability of spare parts & spare parts management & $\theta$ & 0 & C & 0 & 0 & 0 & 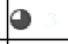 & (1) & Medium \\
\hline maintenance intensity & production controlling & 01 & 0 & 0 & 0 & 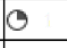 & ( & 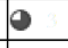 & 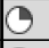 & Low \\
\hline share of external services & production controlling & 12 & 0 & 0 & 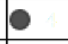 & 0 & 0 & 0 & ( & Low \\
\hline labour cost share & production controlling & 0 & 0 & 0 & C & 0 & 0 & C & 9 & Low \\
\hline material cost share & production controlling & 1 & 0 & 0 & C & 0 & 0 & 0 & 0 & Very Low \\
\hline
\end{tabular}

performance is improved by automatically evaluating the state of production systems and dynamically configuring processing paths for intelligent products and parts. While the implementtation as decentralized production control is proposed, the work deals in detail with a three-machine problem and neglects the dependencies on a higher-level production planning [35].

In summary, it can be concluded that none of the identified approaches includes a systematic integration of different maintenance strategies into autonomous production control. However, if this aspect is not taken into account, these approaches remain largely unsuitable for industrial application, as no valid decisions can be made in the case of unplanned outages or planned maintenance, and thus ultimately the acceptance of such approaches by operational planning staff is not given. In front of this background a comprehensive methodology for integrating maintenance strategies in autonomous production control has been presented by Glawar et al. (2019) [20] and Glawar et al. (2020) [36]. The core of this conceptual model, which is presented in detail in section 5 , is a cost based model for the integrated planning. This model is laid out in section 4 based on the relevant aspects for the integration of maintenance in APC introduced in section 3.

\section{RELEVANT ASPECTS FOR THE INTEGRATION OF MAINTENANCE IN APC}

For the integration of maintenance into APC, an important step is to clarify which maintenance aspects are relevant for the integration decision. For this purpose, an expert survey has been conducted including professionals from industrial sectors, namely semiconductor production, metal processing industry, condition monitoring and automotive industry as well as national and international academic experts. The aim of this survey was to discuss the following question with the experts: "How do you evaluate the individual aspects of maintenance with regard to their relevance for integration into production planning and control (PPC)?" The first step was to discuss which aspects of Plant Maintenance (aka industrial maintenance) are generally important for PPC and for which area of PPC a specific aspect is relevant. Using the pair-wise comparison method, it was finally determined how relevant the individual aspects are for integration into the PPC. The results of this expert survey are presented in Table 2. The essential aspects of maintenance are listed in the first column and evaluated with regard to their relevance for decision-making. In the second column the relevance for the integration into the different dimensions of PPC is shown. A significant finding is that the relevance for the consideration of the individual aspects for the PPC strongly depends on the general operational conditions, especially the degree of automation, production type and flexibility in case of a plant failure. A closer look at the results shows that some aspects are particularly relevant for integration into APC, while other aspects may have a positive influence on the quality of decisions but are not absolutely necessary for integration purpose. In addition, there are other aspects of Plant Maintenance which are particularly important for integration into medium- and longterm production planning as well as production controlling. These decision factors have not been further addresses during the course of the present work.

\subsection{Downtime $\&$ costs}

The time for a shutdown, in case of an occurring failure of the machine, can be estimated either on the basis of empirical knowledge, or calculated on the basis of historical shutdowns. It 
is important to note that the downtime that occurs usually differs significantly depending on whether it is a planned or unplanned shutdown. Since downtime costs correlate with the order situation, the lost contribution margin in the event of a downtime is usually used to calculate the downtime costs. Penalties for delayed order completion are also taken into account, if applicable. Together with the probability of failure, the downtime costs represent an important basis for decisionmaking in production control.

\subsection{Maintenance time $\&$ costs}

The time for a repair can either be estimated on the basis of manufacturer information and empirical knowledge or calculated on the basis of historical data (e.g., mean time to repair MTTR). Usually, when calculating repair costs, a distinction is made between internal and external repair costs, which are usually caused by external services. The underlying share of external services largely determines the repair time and costs. In the case of internal repair costs, the repair time is usually taken into account, taking into account the hourly rates of the personnel required for the repair, depending on their qualifications, and supplemented by the material costs for the necessary spare parts. This applies analogously to the occurring maintenance times \& costs. The repair and maintenance costs calculated in this way are important factors in production control for deciding whether maintenance should be carried out or even brought forward, or whether the risk of a breakdown with subsequent repair should be taken.

\subsection{Spare parts availability}

The information on whether the spare parts required for repair and maintenance are basically available is decisive for the decision within the framework of production control as to whether maintenance is triggered or whether an order is produced on a system with a certain risk of failure. Depending on the type and complexity of a machine as well as the organizational form of maintenance, spare parts availability represents a more or less important decision aspect. In the case that mechanical spare parts can be produced independently with relatively little effort or are outsourced to a service provider via a service contract, it may not be necessary to integrate this decision aspect into production control.

\subsection{Availability of maintenance capacity}

The information as to whether maintenance capacity is available for repair or maintenance is essential in the context of production control in order to make the decision as to whether this should be triggered. Capacities can represent both internal personnel resources and external third-party services, which are usually not available in unlimited quantities. Depending on the type of maintenance organization, this decision aspect is also more or less important. While a capacity check can be very important in a decentralized maintenance organization that has to manage with a narrowly limited capacity, it is less important in an organization that provides sufficient resources centrally.

\subsection{Availability of qualifications}

The qualifications required to perform a particular repair or maintenance task can also play a relevant role in the decision within the framework of production control. However, the significance of this decision aspect depends to a large extent on the complexity of the equipment as well as the available qualifications of the internal personnel resources. While only a small number of qualified personnel resources are generally available for highly complex plant components such as bionic components, the significance decreases for simple mechanical plant components, for which a large proportion of the available personnel resources are qualified.

\subsection{Planned maintenance orders and planned maintenance interval}

Orders that are scheduled for the execution of maintenance are very relevant for the PPC as they tie up capacities. While internal maintenance tasks only reduce the capacity within a period but allow a certain flexibility with regard to sequence planning, externally performed tasks often represent a hard restriction for production control. The basis for these planned maintenance orders are often the defined intervals for (periodic) preventive maintenance. Maintenance interval management thus represents a key success factor for medium-term production planning. It is crucial that this maintenance planning is coordinated with the expected fluctuation in production volumes in order to prevent equipment from being unavailable in a phase of particularly high order levels, while it could be maintained in a phase of low order levels.

\subsection{Probability of failure}

The probability of failure significantly determines the risk of a plant or machine failure during production and thus influences production control decisions. Depending on the maintenance strategy applied, different approaches exist to calculate the probability of failure. In the simplest case, information from the manufacturer or internal empirical values (e.g. Mean Time Between Failure - MTBF) are used to calculate the probability of failure. Often, historical data based on statistical methods, such as the Weibull distribution, can also be used to calculate the probability of failure. Ideally, the probability of failure is determined based on the actual condition of the plant and a corresponding forecast for the next failure.

\subsection{Condition of the plant or machine components}

If the condition of a plant or machine can be reliably measured, estimated or calculated, it represents an essential decision-making factor for the PPS. In the context of mediumterm production planning and spare parts planning, it is possible to react as soon as a component exhibits a critical condition, for example, by ensuring that the corresponding spare parts are available or by initiating planned maintenance. In the context of production control, the risk of failure can be taken into account based on the change in the condition of the machine for example in the context of sequence planning or machine assignment.

\subsection{Technical plant availability}

Technical plant availability, which describes what proportion of the available operating time a plant is technically available, is a key aspect of medium-term production planning. Depending on the availability, the plants are scheduled to a greater or lesser extent. Technical plant availability also represents a hard restriction for the maximum possible production quantity.

\section{DEVELOPMENT OF A COST FUNCTION FOR AN INTEGRATED PLANNING}

Different algorithms can be used to determine the order of the orders within the autonomous production control. Many of these algorithms use a cost function to prioritize or determine the production sequence. For example, when applying the market principle for APC, orders are allocated to individual 


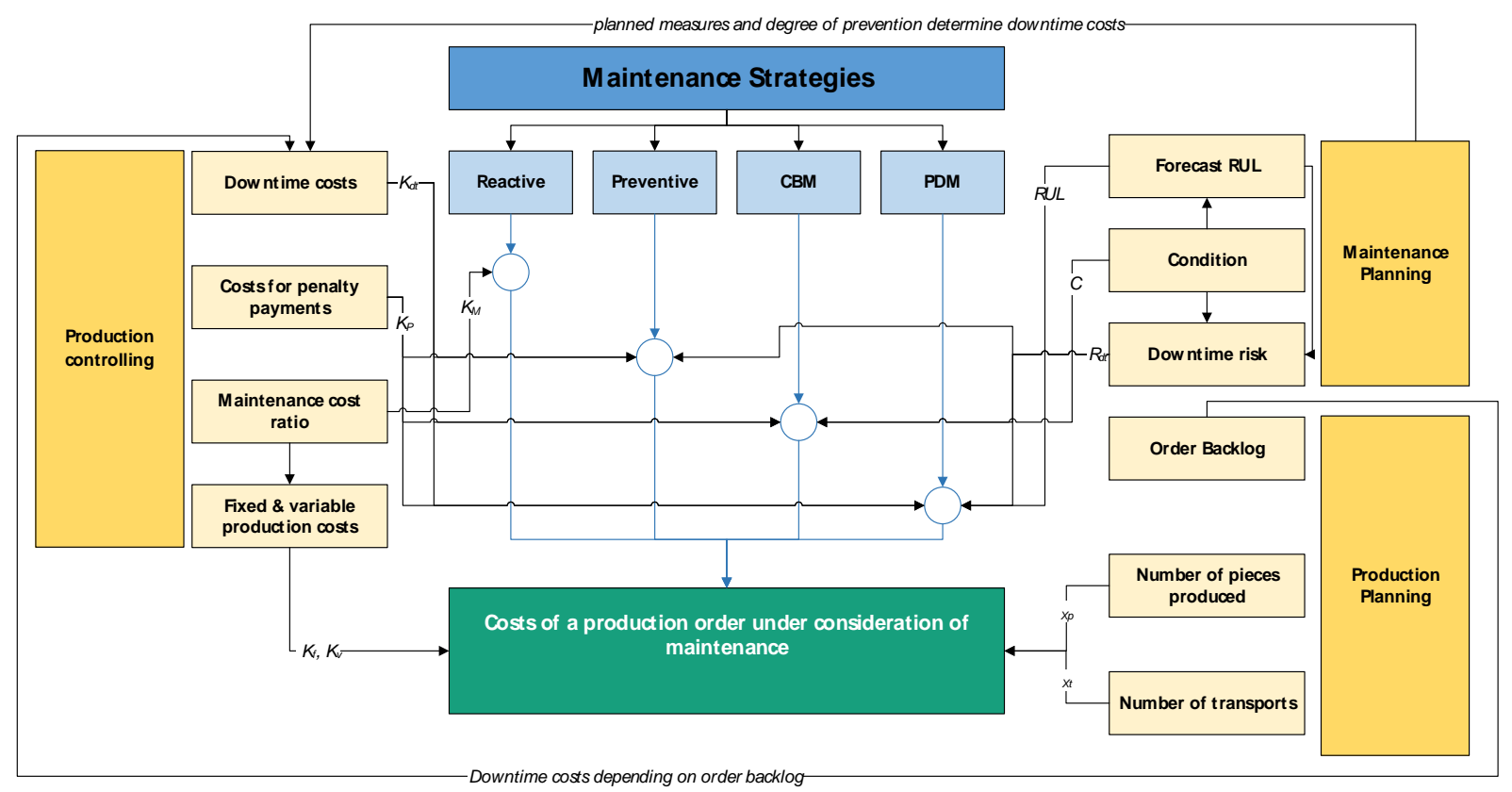

Figure 1. Costs of abased production order under consideration of multiple maintenance strategies [36].

production units based on a cost function. In this paper, a cost function for autonomous production control is developed using the market principle for autonomous production control as an example:

$$
K_{\mathrm{PA}}=\sum K_{\mathrm{S}}+\sum K_{\mathrm{Pf}}+\sum K_{\mathrm{Pv}} \times X_{\mathrm{p}}+\sum K_{\mathrm{Tv}} \times X_{\mathrm{t}}
$$

A possible formulation of the costs of a production order, as shown in (1), is presented by Rötzer and Schwaiger [37]. In this description, the costs of a production order $\left(K_{\mathrm{PA}}\right)$ consist of individual location costs $\left(K_{\mathrm{S}}\right)$ fixed process costs $\left(K_{\mathrm{Pf}}\right)$ variable process costs $\left(K_{\mathrm{Pv}_{\mathrm{v}}}\right)$ and variable transport costs $\left(K_{\mathrm{TV}}\right)$ as well as the production quantity $\left(X_{\mathrm{P}}\right)$ and the number of transports $\left(X_{\mathrm{t}}\right)$. Transportation costs $\left(K_{\mathrm{TV}}\right)$ represent the expenses for the necessary transports $\left(X_{t}\right)$ to move the workload to be produced within the production system. They include, for example, costs for material supply and provision, transports between different workplaces and production facilities, as well as expenses for intermediate, inward and outward storage of the produced worklist. Fixed production costs $\left(K_{\mathrm{Pf}}\right)$. represent the portion of production costs that is independent of the amount of work in process $\left(\mathrm{X}_{\mathrm{P}}\right)$-That is, fixed production costs are constant for each production order. This includes, for example, the expenses for setup between the production orders but also administrative costs for order processing. In comparison, variable production costs $\left(\mathrm{K}_{\mathrm{Pv}}\right)$ depend on the amount of work produced.

Typical variable production costs are, for example, costs for material, auxiliary and operating supplies, expenses for the actual production depending on the processing time, as well as expenses for the necessary energy input during production. The variable process costs of a production thus consist of costs due to production backlog, production time, setup times, and the inventory necessary for production, as well as maintenance costs [38]. In this context, the availability of the machines and the delay of the end of the order are particularly relevant for the evaluation of a production order [39]. For this reason, it is necessary to explicitly add the maintenance-relevant factors in a cost function to describe the costs of a production order.
Since different maintenance strategies make different demands on production control, but also allow for different information, it is advisable to use different cost functions for the different maintenance strategies. The cost functions are successively designed to build on each other, so that it is possible to use them in a production system that uses different maintenance strategies for the different assets and their components.

\subsection{REACTIVE MAINTENANCE STRATEGY}

The reactive maintenance strategy is characterized by the fact that the system components are operated until failure and therefore the failure probability and the associated costs are not relevant for decision-making. This is also reflected in the representation of the cost function of a production order under consideration of reactive maintenance $K_{\mathrm{RM}}$, cf. (2). The cost function takes into account not only the sum of the fixed production costs $K_{\mathrm{f}}$, variable production costs $K_{\mathrm{p}}$, transport costs $K_{\mathrm{t}}$, as well as the current order load $X_{\mathrm{p}}$, and the number of transports $X_{\mathrm{t}}$, but also the maintenance cost ratio $K_{\mathrm{m}}$. The maintenance cost ratio describes the maintenance costs per production quantity produced. The maintenance costs under consideration include the costs for maintenance and repair of the various elements of the production system, the costs for spare parts stocking, and external service costs.

$$
K_{\mathrm{RM}}=\sum K_{\mathrm{f}}+\sum K_{\mathrm{v}} \times X_{\mathrm{p}}+\sum K_{\mathrm{t}} \times X_{\mathrm{t}}+\sum K_{\mathrm{m}} \times X_{\mathrm{p}}
$$

\subsection{PERIODIC PREVENTIVE MAINTENANCE STRATEGY}

In periodic preventive maintenance, measures are planned preventively either time-dependently, for example weekly, quarterly or annually, or load-dependently, for example after a certain number of operating hours or switching operations. Hence, the cost function of a production order, taking into account preventive maintenance $K_{\mathrm{PM}}$, cf. (3). It also takes into account the risk of an unplanned production downtime $R_{d t p}$, 
costs in the event of a downtime event $K_{\mathrm{d} \text {, }}$, as well as any costs for contractual penalties due to schedule variances $K_{\mathrm{P}}$.

The costs in case of a downtime event are, for example, the lost contribution margin of the planned worklist in case of an unplanned downtime, as well as costs for repairs. These downtime costs are dependent on the current order load $X_{\mathrm{p}}$ as shown in (4). The default risk in the case of periodic preventive maintenance $R_{d t p}$, can be calculated based on historical failures. For this purpose, the probability density function $\mathrm{fp}(T S L F)$ is used for integration, where TSLF describes the time since last failure, cf. (5). Normally, a normal distribution is assumed, cf. (6). While the normal distribution is calculated based on historical failures, the expected value is assumed by the MTBF.

$$
\begin{aligned}
& K_{\mathrm{PM}}= \sum K_{\mathrm{f}}+\sum K_{\mathrm{v}} \times X_{\mathrm{p}}+\sum K_{\mathrm{t}} \times X_{\mathrm{t}} \\
&+\sum K_{\mathrm{m}} \times X_{\mathrm{p}}+\sum K_{\mathrm{dt}} \times R_{\mathrm{dtp}}+\sum K_{\mathrm{p}} \times R_{\mathrm{dtp}} \\
& K_{\mathrm{dt}}= \mathrm{f}\left(X_{\mathrm{p}}\right) \\
& R_{\mathrm{dtp}}= \int_{0}^{T S L F} \mathrm{fp}(T S L F) \mathrm{d} T S L F \\
& f p(T S L F)=\frac{1}{\sigma \sqrt{2 \pi}} \mathrm{e}^{-\frac{1}{2}\left(\frac{T S L F-M T B F}{\sigma}\right)^{2}}
\end{aligned}
$$

\subsection{CONDITION-BASED MAINTENANCE STRATEGY}

The cost function of a production order under consideration of condition-based maintenance $K_{\mathrm{CM}}$, cf. (7), corresponds largely to the cost function of preventive maintenance and also includes the risk of an unplanned production downtime $R_{\mathrm{dtc}}$ applying condition-based maintenance strategies. In this case, in which a maintenance task is planned depending on the actual condition of a component, $R_{\text {dtc }}$ is calculated by a condition-based function $\mathrm{fc}$ at the respective time of the condition determination tc and the determined condition $\mathrm{C}$ at this time, cf. (8). The determination of this function is usually based on empirical studies or on already known equations or manufacturer data. In many cases, especially if a complex empirical determination is not economical, it is sufficient to assign a fixed default risk $R_{d t c}$ to defined states $\mathrm{C}$ based on empirical knowledge.

$$
\begin{aligned}
K_{\mathrm{CM}}= & \sum K_{\mathrm{f}}+\sum K_{\mathrm{v}} \times X_{\mathrm{p}}+\sum K_{\mathrm{t}} \times X_{\mathrm{t}} \\
& +\sum K_{\mathrm{m}} \times X_{\mathrm{p}}+\sum K_{\mathrm{dt}} \times R_{\mathrm{dtc}}+\sum K_{\mathrm{p}} \times R_{\mathrm{dtc}} \\
R_{\mathrm{dtc}}= & f c(t c ; C)
\end{aligned}
$$

\subsection{PREDICTIVE MAINTENANCE STRATEGY}

In predictive maintenance ( $\mathrm{PdM})$, maintenance tasks are planned depending on prognosis of remaining useful life (RUL). The cost function of a production order, therefore, takes into account $K_{\mathrm{PdM}}$, cf. (9), the risk of an unplanned production downtime $\left(R_{\text {drpdm }}\right)$. The failure risk is calculated analogous to the condition-based maintenance by a function $\mathrm{fp}$ which is determined by the RUL i.e. the remaining degree of wear and tear of the machine component, cf. (10). This function must also be known or empirically determined.

In (11), a determination of the RUL using a Weibull function is shown. Here, $T$ represents the characteristic life, beta the shape parameter and $w_{1}$ an influence factor to account for changing operating conditions of the Weibull function. In summary,
Figure 1 shows the composition of the developed cost function depending on the applied maintenance strategy and visualizes the relationship between the individual cost factors

$$
\begin{aligned}
K_{\mathrm{PdM}}= & \sum K_{\mathrm{f}}+\sum K_{\mathrm{v}} \times X_{\mathrm{p}}+\sum K_{\mathrm{t}} \times X_{\mathrm{t}} \\
& +\sum K_{\mathrm{m}} \times X_{\mathrm{p}}+\sum K_{\mathrm{dt}} \times R_{\mathrm{dtpdm}} \\
& +\sum K_{\mathrm{p}} \times R_{\mathrm{dtpdm}} \\
R_{\mathrm{dtpdm}} & =\mathrm{fp}(R U L) \\
R U L= & \mathrm{e}^{-\left(\frac{t}{T \times w_{i}}\right)^{\beta}}
\end{aligned}
$$

\section{CONCEPTUAL MODEL FOR INTEGRATING MAINTENANCE STRATEGIES IN APC}

The model for the integration of different maintenance strategies in APC is designed using three subsystems: i) a maintenance system, ii) a system for autonomous production control and iii) a system for production planning. In Figure 2, these subsystems and their interrelations are shown in detail. The system for autonomous production control maps the level for machine-to-machine (M2M) communication of the APC model. It regulates the real-time communication of the different elements of a production system with the aim of autonomously determining a production sequence based on the requirements of the production control system (the production orders) and the current framework conditions of the production system. To achieve this goal, real-time communication between different machine agents (MA), work piece agents (WPA) and resource agents (RA) is necessary (information flow A). An MA represents the different machines and plants of a production system. WPAs represent the open worklist within a production system. Depending on the production environment, an open worklist can be a concrete workpiece, production lot or any clearly identifiable portion of the production quantity. An RA represents further elements of a production system which are of interest for the task of production control. Depending on the production environment, these can be, for example, tools, workstations, measuring equipment, transport equipment and all other resources, which have a significant influence on the determination of the production sequence. The M2M communication between MA, WPA and RA takes place via a Message Transport System (MTS), which communicates between the elements of the production system and an Order Agent (OA) via an Agent Management System (AMS) and a Directory Facilitator (DF). The AMS manages the specific addresses of the individual agents (information flow B). In comparison, the DF manages the specific attributes and properties of each individual agent (information flow C). Examples of these attributes are the probability of failure, downtime costs, and repair and maintenance costs, which are communicated directly from the maintenance system to the DF (information flow D).

Further attributes describe, for example, the ability of an agent to determine which possible production steps can be carried out at the respective MA or which processing times result from this. The MTS distributes messages between the different agents and between agents and OA (information flow E). The MST transports information about the attributes and properties of the respective agents and production orders, which it receives from 
DF and OA. The MST transports this information from a specific address that it receives from AMS to another specific address that is also provided by AMS. The OA also receives information about spare parts availability, maintenance capacity availability, and available qualifications from the maintenance system (information flow F). With this information, taking into account the current production sequence, planned maintenance orders can be defined and confirmed to the maintenance system (information flow G). The operational control of these maintenance orders, as well as the control of production orders, takes place via communication between the various agents and DF and AMS using MTS. The central task of the system for APC is to determine the production sequence based on real-time M2M communication. Different scheduling models can be used to fulfil this task and to determine a sequential order for each of the different production orders provided by the OA. The production orders to be scheduled are typically created and managed by an Enterprise resource planning (ERP) or Manufacturing execution system (MES). In the present work, a "marketplace-based" model is used to illustrate the integration of the system for APC. In this case, the OA receives a demand in the form of a production order from an ERP or MES system. This demand is matched by a supply of capacities of the MAs and RAs representing the production capacities of the production system such as machine resources, work centre resources, tool resources or transport resources. The information necessary to describe the supply is provided to the OA by means of MST via the attributes

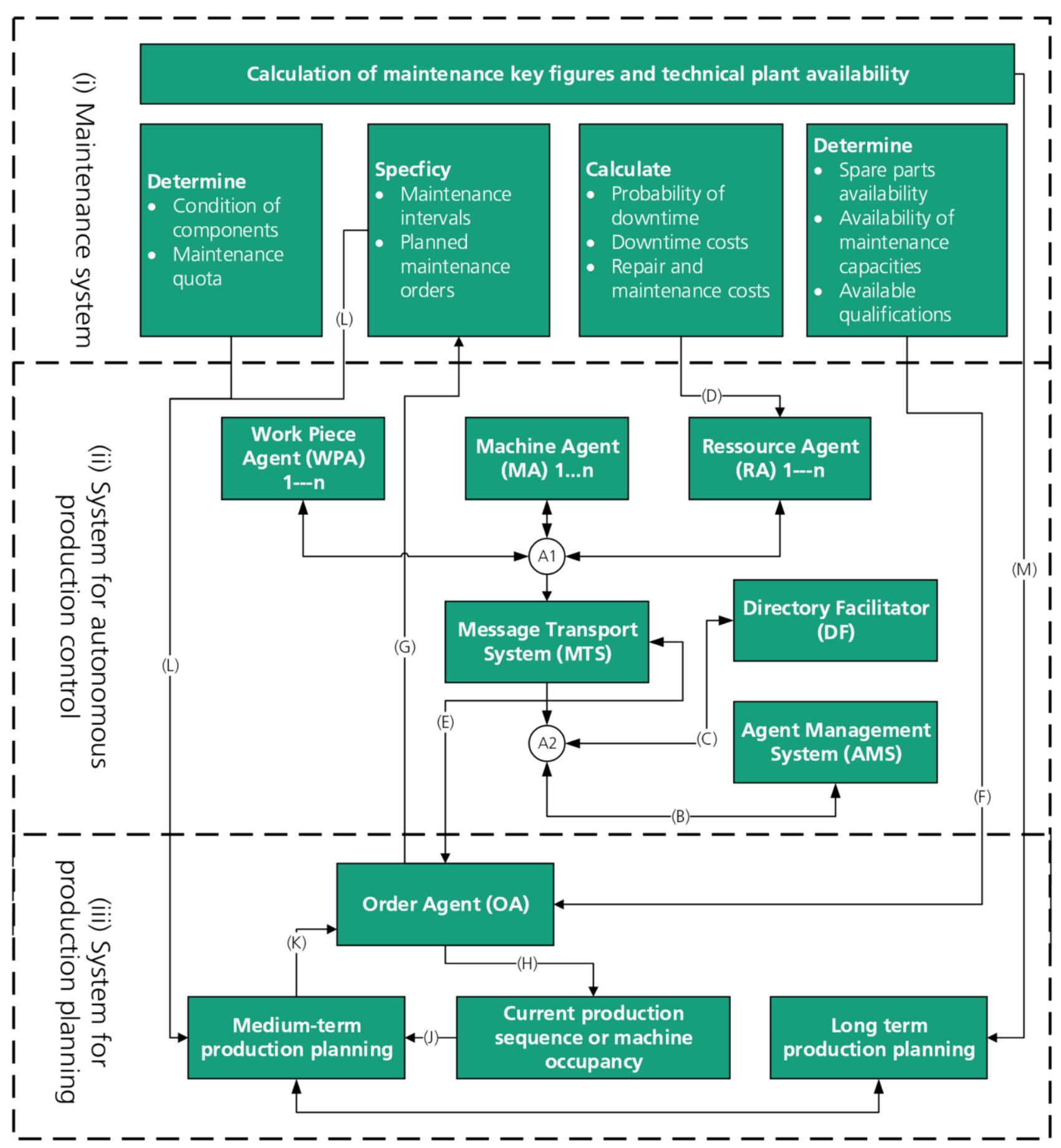

Figure 2. Process model for the integrated planning of maintenance and APC [36]. 
of the production resources relevant for the production order in question, which are managed in the DF.

$$
P=\frac{1}{\left(t_{\mathrm{i}}-t_{\mathrm{e}}\right)} \times\left(t_{\mathrm{c}}-t_{\mathrm{i}}\right) \times K_{\min }
$$

Using the information on supply and demand, OA is able to determine the priority of each production order, cf. (12). The priority $P$ is calculated by taking into account the desired completion date $t_{c}$, the possible order start time $t_{1}$, the order receipt time $t_{\mathrm{e}}$, and a priority factor $K_{\mathrm{min}}$. The OA can calculate the priority factor necessary to determine the priority using the information received from the MTS based on the information managed in the DF. To determine the priority factor, the cost function, presented in this paper, is used here.

$$
p_{\text {min }}=\min [p(x)] ; 0<x<n_{M A}
$$

Due to the structure of the underlying cost function, the priority of a manufacturing order increases the higher the costs of the manufacturing order and therefore the priority factor. Similarly, the greater the difference between the current time and the incoming order, the higher the priority. The higher the desired production duration of the worklist to be produced, the lower the priority of the underlying manufacturing order is calculated. Since it is usually assumed that both the variable production costs and the risk of an unplanned downtime differ between the different machines and plants of a production system, it is necessary to calculate the priority factor for the number of possible MA ( $\left.n_{\mathrm{MA}}\right)$, and then determine the minimum of the possible priority factors $\left(p_{\min }\right)$, cf. (13). Based on this minimum, the final step is to determine the sequence rank $N$ of the production order to be produced on the assigned MA, cf. (14). For this purpose, the priority rank $(P(i))$ of the individual available Production Orders $\left(P A_{\mathrm{n}}\right)$, is determined in order of the minimum priority:

$$
N=\operatorname{rank}(\mathrm{P}(\mathrm{i}))<\min \left\{P A_{n}\right\} \text {. }
$$

Based on the sequence rank $N$ and the lead time $t_{\mathrm{pt}}$, which the OA can determine using the information it receives from DF via the MTS and the current time $t_{\text {act }}$, the OA can determine the estimated time of completion $\mathrm{t}_{\mathrm{N}}$, (15), and communicate this together with the defined production sequence to the production planning system (information flow j). For example, the OA provides this information to a MES via the MST or an alternative interface.

$$
t_{\mathrm{N}}=t_{\mathrm{act}}+\sum_{0}^{N} t_{\mathrm{pt}}
$$

\section{OUTLOOK AND FURTHER RESEARCH}

\subsection{Evaluation of Economic Plausibility}

In further research of Glawar et al. (2021) the presented model has been implemented and evaluated [40]. Since an implementation in a real time environment is yet hard to realize an implementation using an agent-based simulation approach based on a real industrial use case in the automotive industry has been realized. On this basis, the conditions for a successful, and cost-effective implementation of the model in industry are derived. In this Use-case the benefits of integrating maintenance strategies in APC can be described as follows [40]: a. An increase in on-time delivery of more than $9 \%$ by reducing schedule deviations due to backlogs of production jobs. Since the condition of a machine is already taken into consideration during the production control, even a simultaneous failure of several machines has little impact on the adherence to delivery dates.

b. A reduction in the cost of manual rescheduling of approximately $€ 29,500$ per year, since in the event of an unplanned machine failure the sequence and machine assignment can be adjusted autonomously.

c. Increase of the uptime by using the potential of modern maintenance strategies by approx. $4 \%$ to over $96 \%$ and thus a reduction of maintenance costs of approx. $€$ 52,000 per year.

d. Increase in productivity, which is defined as parts produced per hour, by over $5.6 \%$.

\subsection{Integration into maintenance cost controlling}

The cost function developed in this thesis aims at integrating the relevant aspects of maintenance for autonomous production control. In a further step, this cost consideration can also be used as a basis for integration into maintenance cost controlling. Such an analysis enables the formalization of the relationship between key figures such as the proportion of external costs or the maintenance ratio and the operational logistical targets such as lead time and adherence to delivery dates as well as the productivity of the production system. The maintenance ratio describes the maintenance costs incurred in relation to a period under consideration. It is therefore an essential component of production costs and can already be used in rough-cut planning and in sequencing. This makes it possible to consider the resulting effects at the tactical level and to derive measures for achieving an overall optimum, independent of a fixed defined maintenance budget.

Existing models for maintenance cost controlling such as the Cost prove model [41] model planned and unplanned maintenance costs and attempt to derive optimization measures based on any deviation from a defined budget in order to achieve the ideal operating point between planned and unplanned measures for maintenance. In comparison, by taking into account the developed cost function depending on the current and future expected production program as well as the current risk of failure of the equipment necessary for the workers of this production program, the Maintenance Costs are dynamically adjusted.

This creates transparency for the performance of maintenance by quantifying the benefit of concrete measures on the operating result in costs and thus justifying, for example, the exceeding of a target budget while ensuring adherence to schedules and productivity.

An example of integration in maintenance cost controlling is shown in Figure 3. Maintenance cost controlling supplies relevant cost variables to production control, which pursues the goal of minimizing the costs for a production order while taking maintenance into account. If a deviation from the original maintenance budget occurs, the effect on productivity and ontime delivery is used in a mathematical reference model to optimize maintenance cost controlling. This results in new target costs for maintenance, which influences the initiation of planned measures depending on the risk of failure and the respective machine condition. 


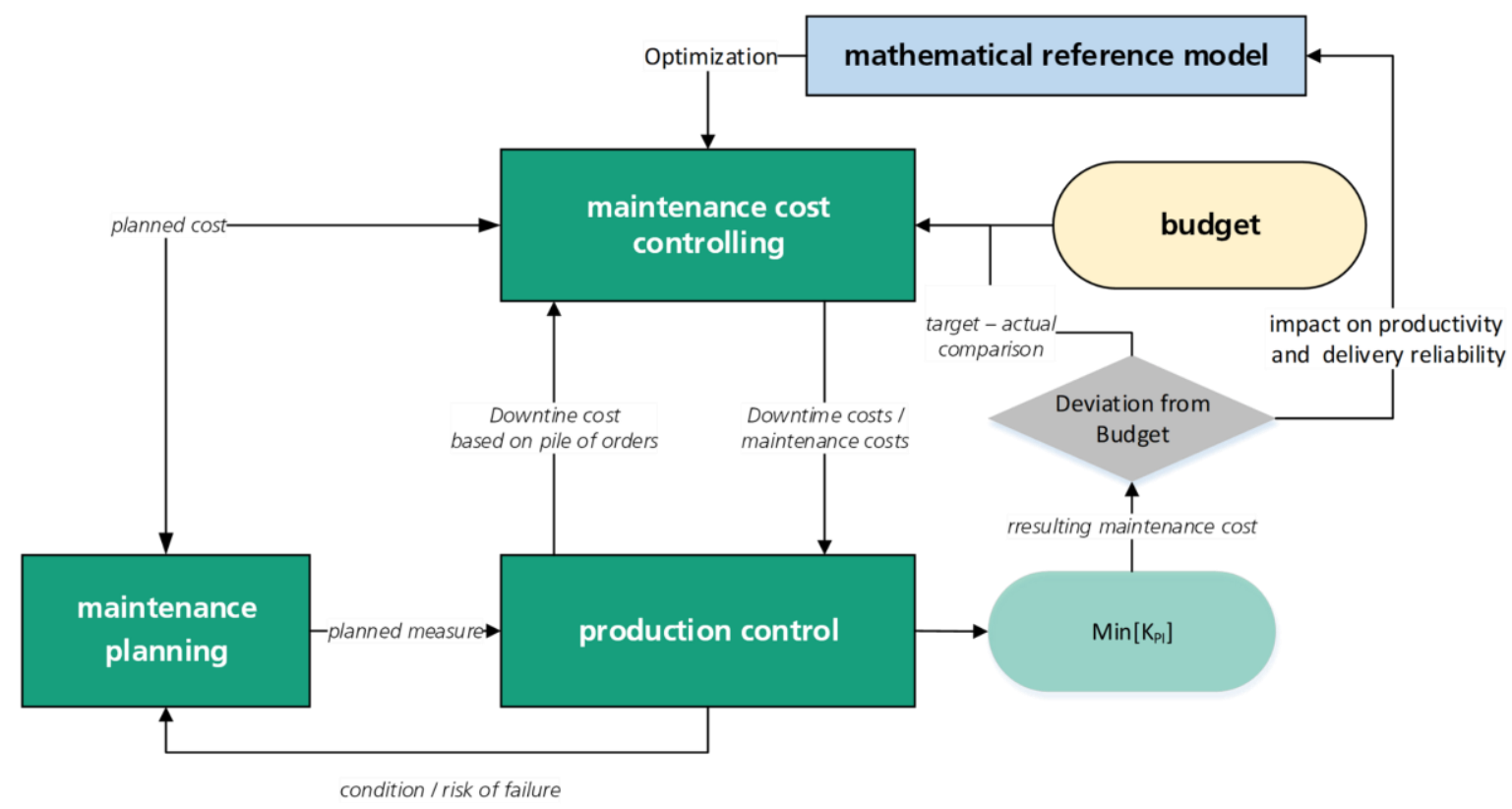

Figure 3. Integration into maintenance cost controlling.

In order to create such a mathematical reference model, it is expedient to differentiate between planned and unplanned cost factors, as explained by Ansari [38] and to model these in order to achieve an overall optimum.

\section{CONCLUSIONS}

In the present paper a novel model for integrating maintenance strategies in autonomous production control has been presented. Relevant decision aspects have been discussed and a cost function for an integrated planning using a marketbased approach have been laid out. It is based on the key elements of a CPPS and their relations to establish a complete but fully, efficiently integrated component in PPC.

Essential findings are the identified and evaluated aspects of maintenance which are decision relevant for the integration into the production control. The most relevant aspects are taken into account in the developed cost function for integrated planning, thus providing a robust basis for the implementation of APC in industrial practice. Only through clear guidelines on how autonomous control behaves in the event of a failure and how the case of an increased risk of failure is taken into account, a acceptance for the implementation of APC can be achieved.

Against this background, the developed cost-based model contributes to bringing approaches to APC a further step towards implementation maturity and thus provides an innovative approach to communication between production and maintenance planning - both from a practical and a scientific point of view.

However, further research questions remain open:

1) The implementation of the present process model in a real production environment and a corresponding evaluation of the benefits in industrial practice represent the logical next step. This requires a well-thought-out roadmap, since such an implementation deeply affects different areas of a production system. In addition, there is the challenge of preparing personnel for the new way of working using autonomous production control and providing appropriate qualification measures in good time.
2) The present model is limited to the mapping of a manufacturing area and negates at this point the dependencies with respect to the higher-level planning to the present or subsequent areas of the production system. In particular, the challenges to the integration of autonomous and human agents have to be addressed.

3) Similarly, the impact of short-term production control at the operational level on the tactical and strategic levels, such as production controlling, poses exciting challenges for further research activities. In particular, integration into maintenance cost controlling, as outlined schematically in section 6.2 can offer a significant contribution to quantifying the contribution of maintenance to the achievement of operational targets in this context.

4) Approaches that make use of artificial intelligence methods represent interesting alternatives for the relatively simple market-based model used in the present model- In this context, reinforcement learning approaches in particular represent an alternative which, in the view of the author, should be explored in this context in the future.

5) In order to be able to apply this approach easily and quickly to further use cases in the future, research should be conducted in the direction of automated parameter optimization, for example by means of simulation studies.

\section{ACKNOWLEDGEMENT}

This work has been supported by the European Commission through the H2020 project EPIC (Grant No. 739592).

\section{REFERENCES}

[1] T. Bauernhansl, R. Miehe, Industrielle Produktion-Historie, Treiber und Ausblick. Fabrikbetriebslehre 1, Springer Vieweg, Berlin, Heidelberg, 2020, pp. 1-33.

[2] D. Spath, E. Westkämper, H.-J. Bullinger, H.-J. Warnecke, Neue Entwicklungen in der Unternehmensorganisation. Springer Vieweg, 2017. 
[3] E. Rauch, P. Dallasega, D. T. Matt, Complexity reduction in engineer-to order industry through real-time capable production planning and control. Production Engineering, 12(3-4), 2018, pp. 341-352. DOI: $10.1007 /$ S11740-018-0809-0

[4] S. Luke, C. Cioffi, L- Panait, K. M. Sullivan, G. C. Balan, MASON: A multiagent simulation environment, SIMULATION, 81(7), 2005, pp. 517-527.

DOI: $\underline{10.1177 \% 2 \mathrm{~F} 0037549705058073}$

[5] V. Gallina, L. Lingitz, M. Karner, A new perspective of the cyberphysical production planning system, 16th IMEKO TC10 Conference, Berlin, Germany, 3-4 September 2019. Online [Accessed 8 September 2021] https://www.imeko.org/publications/tc10-2019/IMEKOTC10-2019-008.pdf

[6] A. Kinz, R. Bernerstaetter, H. Biedermann, Lean smart maintenance - efficient and effective asset management for smart factories. MOTSP 2016, Porec, Istria, Croatia, 1-3 June 2016, 8 pp.

[7] O. Schmiedbauer, H. T. Maier, H. Biedermann, Evolution of a lean smart maintenance maturity model towards the new age of industry 4.0, 2020

DOI: $\underline{10.15488 / 9649}$

[8] F. Pauker, T. Frühwirth, B. Kittl, W. Kastner, A systematic approach to OPC UA information model design. Procedia CIRP, 2016, 57:321-326.

DOI: $10.1016 /$ i.procir.2016.11.056

[9] M. Ulrich, D. Bachlechner, Wirtschaftliche Bewertung von KI in der Praxis, HMD Praxis der Wirtschaftsinformatik, 2020, 57(1):46-59 [in German]. DOI: $10.1365 /$ s40702-019-00576-9

[10] F. Ansari, R. Glawar T. Nemeth, PriMa: A Prescriptive Maintenance Model for Cyber-Physical Production Systems, International Journal of Computer Integrated Manufacturing, Vol. 32, Issue 4-5, 2019, pp. 482-503.

DOI: $10.1080 / 0951192 X .2019 .1571236$

[11] M. Henke, T. Heller, Smart maintenance - der Weg vom Status quo zur Zielvision. acatech STUDIE, 2019, 68 pp. [in German].

[12] E. Uhlmann, E. Hohwieler, M. Kraft, Selbstorganisierende Produktion, Agenten intelligenter Objekte koordinieren und steuern den Produktionsablauf. Fraunhofer IPK Berlin, GITO Verlag, 2013, Berlin, pp. 57-61 [in German].

[13] L. Monostori, B. Kádár, T. Bauernhansl, S. Kondoh, S. Kumara G. Reinhart, O. Sauer, G. Schuh, W. Sihn, K. Ueda, Cyber-physical systems in manufacturing, CIRP Annals, 65(2), 2016, pp. 621-641. DOI: $10.1016 /$ i.cirp. 2016.06.005

[14] B. Vogel-Heuser, D. Schütz, T. Schöler, S. Pröll, S. Jeschke, D. Ewert, O. Niggemann, S. Windmann, U. Berger, C. Lehmann, Agentenbasierte cyber-physische Produktionssysteme. Anwendungen für die Industrie 4.0, atp magazin, 57(09), 2016, pp. 36-45 [in German]

[15] F. Förster, A. Schier, M. Henke, M. Ten Hompel, Dynamische Risikoorientierung durch Predictive Analytics am Beispiel der Instandhaltungsplanung. Logistics Journal. Proceedings, 2019(12), pp. 1-9 [in German].

DOI: $10.2195 /$ li Proc foerster de 20191201

[16] N. O. Fernandes, T. Martins, S. Carmo-Silva, Improving materials flow through autonomous production control. Journal of Industrial and Production Engineering, 35(5), 2018, pp. 319-327. DOI: $10.1080 / 21681015.2018 .1479895$

[17] J. Zhang, Multi-Agent-Based Production Planning and Control, John Wiley \& Sons, 2017, ISBN 9781118890080 (pdf).

[18] G. Kasakow, N. Menck, J. C. Aurich, Event-driven production planning and control based on individual customer orders, Procedia CIRP, 57, 2016, pp. 434-438.

DOI: $10.1016 /$ i.procir.2016.11.075

[19] R. Cupek, A. Ziebinski, L. Huczala, H. Erdogan, Agent-based manufacturing execution systems for short-series production scheduling. Computers in Industry 82, 2016, pp. 245-258. DOI: $10.1016 /$ i.compind.2016.07.009
[20] R. Glawar, F. Ansari, C. Kardos, K. Matyas, W. Sihn, Conceptual design of an integrated autonomous production control model in association with a prescriptive maintenance model (prima). Procedia CIRP, 80, 2019, pages 482-487. DOI: 10.1016/J.PROCIR.2019.01.047

[21] H. Meissner, R. Ilsen, J. C. Aurich, Analysis of control architectures in the context of industry 4.0. Procedia CIRP, 2017, 62:165-169.

DOI: $10.1016 /$ i.procir.2016.06.113

[22] S. Grundstein, S. Schukraft, M. Görges, B. Scholz-Reiter, An approach for applying autonomous production control methods with central production planning. Int J Syst Appl Eng Dev, 7(4), 2013, pp.167-174. Online [Accessed 8 September 2021] https://www.naun.org/main/UPress/saed/d012014-130.pdf

[23] L. Martins, N. O. Fernandes, M. L. R. Varela, Autonomous production control: A literature review. In International Conference on Innovation, Engineering and Entrepreneurship, 2018, pp 425-431. DOI: $10.1007 / 978-3-319-91334-6 \quad 58$

[24] S. Mantravadi, C. Li, C. Møller, Multi-agent manufacturing execution system (MES): Concept, architecture \& $\mathrm{ml}$ algorithm for a smart factory case, Proceedings of the 21st International Conference on Enterprise Information Systems, SCITEPRESS Science and Technology Publications, 2019, pp. 477-482. DOI: $10.5220 / 0007768904770482$

[25] D. Pantförder, F. Mayer, C. Diedrich, P. Göhner, M. Weyrich, B. Vogel-Heuser, Agentenbasierte dynamische Rekonfiguration von vernetzten intelligenten Produktionsanlagen. In Handbuch Industrie 4.0 Bd. 2, 2017. pp. 31-44 [in German]. DOI: $10.1007 / 978-3-658-04682-87$

[26] M. Hoffmann, J. Aro, C. Büscher, T. Meisen, Intelligente Produktionssteuerung und Automatisierung, ProductivITy, GITO Berlin, 2016, pp. 17-20 [in German].

[27] I. Graessler, A. Poehler, Integration of a Digital Twin as Human Representation in a Scheduling Procedure of a Cyber-Physical Production System, IEEE International Conference on Industrial Engineering and Engineering Management (IEEM), Singapore, 10-13 December 2017, pp. 289-293. DOI: $10.1109 /$ IEEM.2017.8289898

[28] S. Mayer, C. Endisch, Adaptive production control in a modular assembly system based on partial look-ahead scheduling, IEEE International Conference on Mechatronics (ICM), Ilmenau, Germany, 18-20 March 2019, vol. 1, pp. 293-300. DOI: $10.1109 /$ ICMECH.2019.8722904

[29] J. Zou, Q. Chang, X. Ou, J. Arinez, G. Xiao, Resilient adaptive control based on renewal particle swarm optimization to improve production system energy efficiency. Journal of Manufacturing Systems, 2019, vol. 50, pp. 135-145. DOI: $10.1016 /$ i.jmsy.2018.12.007

[30] T. Jamrus, C.-F. Chien, M. Gen, K. Sethanan, Hybrid particle swarm optimization combined with genetic operators for flexible job-shop scheduling under uncertain processing time for semiconductor manufacturing, IEEE Transactions on Semiconductor Manufacturing, 31(1), 2018, pp. 32-41. DOI: $10.1109 /$ TSM.2017.2758380

[31] D. Gyulai, A. Pfeiffer, B. Kádár, L. Monostori, Simulation-based production planning and execution control for reconfigurable assembly cells. Procedia CIRP, 57, 2016, pp. 445-450. DOI: $10.1016 /$ J.PROCIR.2016.11.077

[32] A. Kuhnle, N. Röhrig, G. Lanza, Autonomous order dispatching in the semiconductor industry using reinforcement learning. Procedia CIRP, 79, 2019, pp. 391-396.

DOI: $10.1016 /$ i.procir.2019.02.101

[33] S. Erol, W. Sihn, Intelligent production planning and control in the cloud - towards a scalable software architecture. Procedia CIRP, 62, 2017, pp. 571-576. DOI: $10.1016 /$ i.procir.2017.01.003

[34] J. Vallhagen, T. Almgren, K. Thörnblad, Advanced use of data as an enabler for adaptive production control using mathematical optimization - an application of industry 4.0 principles. Procedia 
Manufacturing, 11, 2017, pp. 663-670.

DOI: $10.1016 /$ i.promfg. 2017.07 .165

[35] F. Wang, Y. Lu, F. Ju, Condition-based real-time production control for smart manufacturing systems, 2018 IEEE 14th International Conference on Automation Science and Engineering (CASE), Munich, Germany, 20-24 August 2018, pp. 1052-1057. DOI: $10.1109 /$ COASE.2018.8560389

[36] R. Glawar, F. Ansari, Z. J. Viharos, K. Matyas, W. Sihn, A costbased model for integrating maintenance strategies in autonomous production control. 17th IMEKO TC 10 Virtual conference, 2022 October 2020, pp. 258 -264. Online [Accessed 8 September 2021]

https://www.imeko.org/publications/tc10-2020/IMEKOTC10-2020-037.pdf

[37] S. Rötzer, W. Schwaiger, Forschungsbericht zum Projekt: „Kosten und CO2-emissionen im Produktionsnetzwerk von Magna Europe", In: H. Biedermann, Industrial Engineering und Management. Technoökonomische Forschung und Praxis, Wiesbaden: Springer Gabler, 2016, pp. 237-246.

[38] M. Haoues, M. Dahane, K. N. Mouss, N. Rezg, Production planning in integrated maintenance context for multi-period multi- product failure-prone single-machine, IEEE 18th Conference on Emerging Technologies \& Factory Automation (ETFA), Cagliari, Italy, 10-13 September 2013, pp. 1-8.

DOI: 10.1109 /ETFA.2013.6647980

[39] A. Berrichi, F. Yalaoui, Bi objective artificial immune algorithms to the joint production scheduling and maintenance planning, IEEE International Conference on Control, Decision and Information Technologies (CoDIT), Hammamet, Tunisia, 6-8 May 2013, pp. 810-814. DOI: $10.1109 /$ CoDIT.2013.6689647

[40] R. Glawar, F. Ansari, K. Matyas, Evaluation of Economic Plausibility of Integrating Maintenance Strategies in Autonomous Production Control: A Case Study, Automotive Industry, 2021, 7th IFAC Symposium on Information Control Problems in Manufacturing (in print).

[41] F. Ansari, Meta-analysis of knowledge assets for continuous improvement of maintenance cost controlling. Faculty of Science and Technology, Thesis, University of Siegen, 2014, 169 pp. 